\title{
Post Construction and Long Term Settlement of an Embankment Dam Computed with Two Constitutive Models
}

\author{
Amjad Hussain Bhutto \\ Department of Civil Engineering, Quaid- \\ e-Awam University of Engineering \\ Science and Technology, \\ Nawabshah, Pakistan \\ amjadbhutto62@gmail.com
}

\author{
Muhammad Auchar Zardari \\ Department of Civil Engineering, Quaid- \\ e-Awam University, of Engineering, \\ Science \& Technology, \\ Nawabshah, Pakistan \\ muhammad.auchar@quest.edu.pk
}

\author{
Shahnawaz Zardari \\ Department of Civil Engineering, Quaid- \\ e-Awam University of Engineering, \\ Science \& Technology, \\ Nawabshah, Pakistan \\ shahnawazzardari@gmail.com
}

\author{
Riaz Bhanbhro \\ Department of Civil Engineering, Quaid- \\ e-Awam University, of Engineering \\ Science and Technology, \\ Nawabshah, Pakistan \\ riaz@quest.edu.pk
}

\author{
Ghulam Shabir Bhurgri \\ Department of Civil Engineering, Quaid- \\ e-Awam University of Engineering \\ Science and Technology, \\ Nawabshah, Pakistan \\ ghulamshabirbhurgri14@gmail.com
}

\author{
Bashir Ahmed Memon \\ Department of Civil Engineering, Quaid- \\ e-Awam University, of Engineering \\ Science and Technology, \\ Nawabshah, Pakistan \\ bashir_m@hotmail.com
}

\begin{abstract}
For the settlement computation of an embankment dam, the soil stiffness is of great importance. Unfortunately, due to the lack of funds allocated for geotechnical investigation, stiffness parameters are commonly not evaluated as compared to strength properties. As a result, this may create hindrance in the use of advanced constitutive models such as Hardening Soil Model (HSM). In this study, the settlement with respect to depth and long term settlement of an embankment dam computed with Mohr-Coulomb Model (MCM) is compared with that of HSM applied to foundation soil only with limited data on stiffness. The results show that the MCM overestimated settlement in comparison with HSM. The settlement increment of MCM, in comparison with HSM, at the crest and at the depth of $120 \mathrm{~m}$ was $53 \%$ and $82 \%$ respectively after the filling of the reservoir. The settlement computed with MCM and HSM were $2.9 \%$ and $1.35 \%$ of the dam height. It can be interpreted that the settlement predicted with MCM is unrealistically high due to the single constant value of modulus of elasticity (MOE), while the predictions of HSM are in agreement with the literature. In addition, the long term settlement computed using MCM is about $59 \%$ higher than that of HSM for the condition after the filling of the reservoir. This paper shows that the settlement of an embankment dam could be predicted reliably by using HSM even when a limited number of stiffness data is available.
\end{abstract}

Keywords-long term settlement; embankment dam; settlement with respect to depth; stiffness; crest

\section{INTRODUCTION}

In Pakistan, the construction of embankment dams is being given top priority to meet the shortage of electricity and water for drinking and irrigation purposes. Depending upon the Corresponding author: Amjad Hussain Bhutto requirements and geology of the site, an embankment dam may be designed to last for hundreds of years. In order to ensure the safety of the dam, stability during various operational stages [12] and possible settlement play an important role [3-5]. Both stability and settlement of an embankment dam could be evaluated with the help of modern numerical tools based on finite element methods. In geotechnical engineering, there are various software programs, which require some soil properties as input to compute the stability and settlement of an embankment dam. Normally, stability is given high priority as compared to settlement. As a result, more focus is given on the determination of soil material properties that are required for stability estimations during the geotechnical investigation process [6]. The stability of an embankment dam is assessed based on factor of safety by using the Mohr-Coulomb model (MCM) to represent stress strain soil behavior. However, the settlement of an embankment dam is also equally important. The use of MCM for the computation of settlement is not considered reliable [7-8], since it does not include stress dependent stiffness, therefore, the settlement predicted could be unrealistically higher with respect to the depth of an embankment dam. In such a situation, it might be advantageous [9] to adopt advanced material models like the Hardening Soil Model (HSM) for settlement computations. Such model types require more material parameters that may be determined through laboratory or field tests. Due to the limited available funding for geotechnical investigation, it might not be possible to conduct more detailed tests that could help in settlement evaluation. This type of problem requires evaluating material properties of HSM from the available material parameters of 
MCM. Therefore, it is interesting to compare settlement with respect to depth, and long-term settlement computed with MCM and HSM. The focus of this paper is to understand how much reliable prediction of the settlement of an embankment could be made by using HSM even by utilizing a limited number of parameters obtained from laboratory tests.

\section{MATERIALS AND METHODS}

Settlement with respect to depth and long term settlement werre computed for an embankment dam called Nai Gaj dam located in Dadu district, Sindh, Pakistan. The calculations were carried out using the Plaxis 2D software [10] which is widely used for analysis of various geotechnical problems. Initially, the settlement was computed with MCM [10]. The predictions made with MCM showed more settlement as compared to the values of similar type of embankment dams mentioned in the literature [14]. Afterwards, four main zones with respect to large volume were identified. These zones were sandy gravel, clay core, random fill, and sandy siltstone (Figure1). HSM was applied to the above-mentioned four zones of the dam and the MCM was used for the remaining zones.
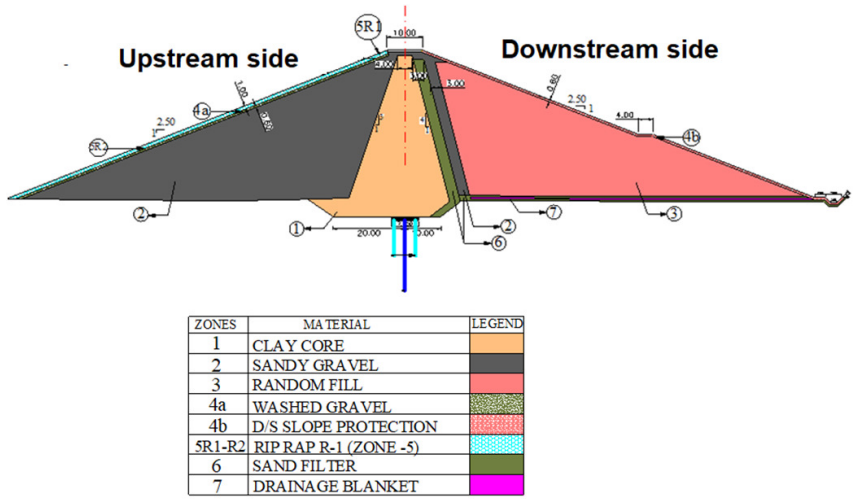

Fig. 1. Cross section of the Nai Gaj dam

Since the focus of this paper is to predict the settlement of the dam, it is relevant to describe that the modulus of elasticity (MOE) is of vital importance for settlement computations. Real soils exhibit stress dependent stiffness, whereas MCM uses a single value of MOE, which may result in overestimation of settlement for embankment dams. On the other hand, the HSM uses three different types of stiffness, which are stress dependent. The stiffness values used in MCM are mentioned as [10]:

$$
E_{50}=E_{50}^{r e f}\left(\frac{c \cos \varphi-\sigma_{3}^{\prime} \sin \varphi}{\cos \varphi+p^{r e f} \sin \varphi}\right)^{m}
$$

where $E_{50}$ is the confining stress dependent stiffness modulus for primary loading, $E_{50}^{r e f}$ is the secant stiffness in standard drained triaxial test, $c$ is cohesion, $\varphi$ is the friction angle of soil, $\mathrm{P}^{\mathrm{ref}}$ is the reference stress for stiffness $(100 \mathrm{kPa}), \sigma_{3}^{\prime}$ is minor effective principle stress, and $m$ is the power for stress level dependency of stiffness. For Norwegian sands and silts, the value of $m$ is reported to be 0.5 [11]. However, for most soils the values of $m$ are ranging from 0.5 to 1 [12].

$$
E_{u r}=E_{u r}^{r e f}\left(\frac{c \cos \varphi-\sigma_{3}^{\prime} \sin \varphi}{\cos \varphi+p^{r e f} \sin \varphi}\right)^{m}
$$

$E_{u r}$ is the stress dependent stiffness modulus for unloading and reloading, $E_{u r}^{\text {ref }}$ reference Young's modulus for unloading and reloading corresponding to the reference pressure $P^{r e f}$ of $100 \mathrm{kPa}$.

$$
E_{\text {oed }}=E_{\text {oed }}^{r e f}\left(\frac{c \cos \varphi-\frac{\sigma_{3}^{\prime}}{K_{0}^{n c}} \sin \varphi}{\cos \varphi+p^{r e f} \sin \varphi}\right)^{m}
$$

$E_{\text {oed }}$ is a tangent stiffness modulus that can be determined from an oedometer test, $E_{o e d}^{r e f}$ is tangent stiffness at a vertical stress of reference pressure $P^{r e f} 100=\mathrm{kPa}, K_{o}^{N C}$ is $K_{o}$ value for normal consolidation.

Figure 2 presents the procedure for determination of $E_{50}$ and $E_{u r}$. Figure 3 illustrates the method of finding $E_{\text {oed }}$.

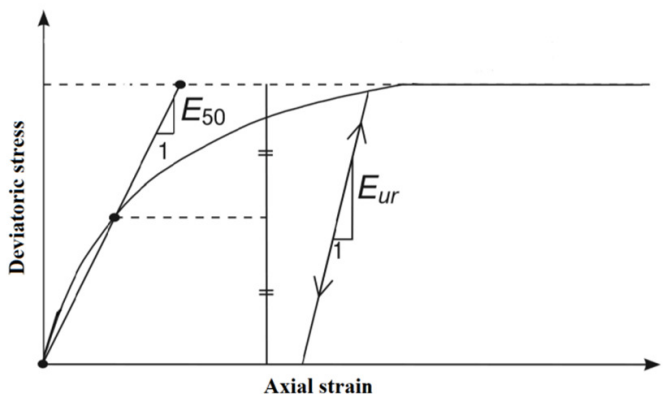

Fig. 2. Procedure for evaluation of $E_{50}$ and $E_{u r}$ from drained triaxial test

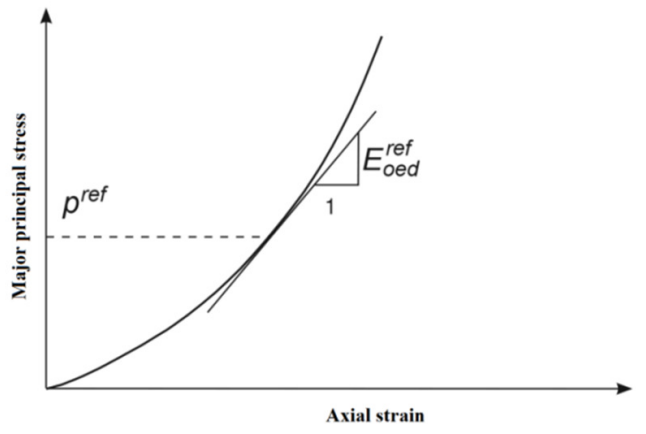

Fig. 3. Method of finding the value of $E_{\text {oed }}^{\text {ref }}$ from the oedometer test

As mentioned above there is a lack of data regarding stiffness behavior of soils as compared to that of strength mainly due to the testing cost. In order to reduce this cost, the following relations regarding stiffness parameters are found to be valuable for computation of settlement $[6,10]$ :

$$
E_{50}^{r e f}=E_{\text {oed }}^{r e f} \quad \text { and } \quad E_{u r}^{r e f}=3 E_{50}^{r e f}
$$

In this paper, the above correlations have been utilized for computation of settlement of the dam by using HSM separately for four zones of the dam. The dam is 59 meter high with a designed maximum flood water level of $56.6 \mathrm{~m}$. Details regarding the rising of the dam and material properties are described in [13]. 


\section{RESULTS AND DISCUSSION}

\section{A. Comparison of Dam Settlement with Respect to Depth Computed with MCM and HSM}

At first, settlement of the dam was computed by applying MCM to all zones. For sake of convenience this is referred to as condition 1. In the second case, HSM was applied separately to the four main zones (clay core, sandy gravel, random fill, sandy siltstone) and MCM was used for the remaining materials (condition 2). The settlements were determined along the central axis of the dam and were computed up to a depth of $120 \mathrm{~m}$ with an interval of $20 \mathrm{~m}$ as shown in Figure 4 . The settlement with respect to depth response of the dam when computed with MCM (condition 1) and HSM applied to clay core, sandy gravel, random fill (condition 2) for the end of construction (EC) and after the filling of reservoir (AFR) are respectively given in Figures 5 to 10.

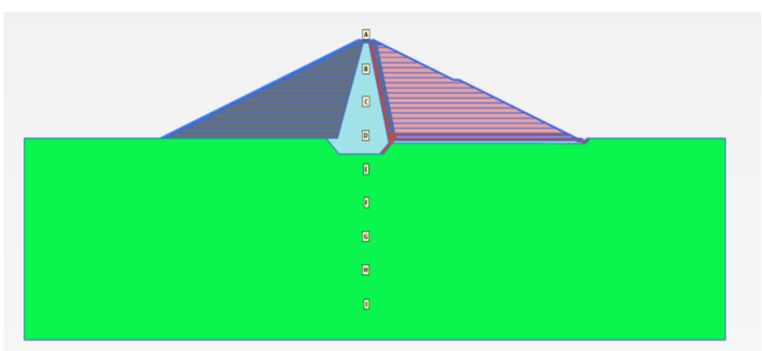

Fig. 4. The settlement of the dam was computed on the central axis of the dam with respect to depth at $20 \mathrm{~m}$ intervals

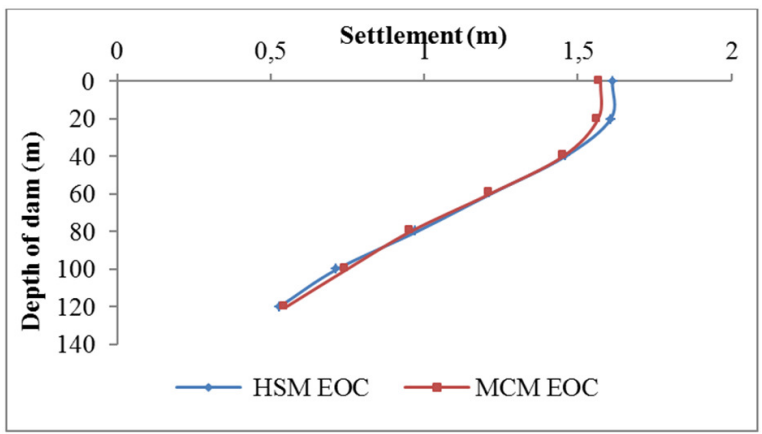

Fig. 5. Comparison of settlement of the dam with respect to depth for EC computed with MCM and HSM applied to clay core only

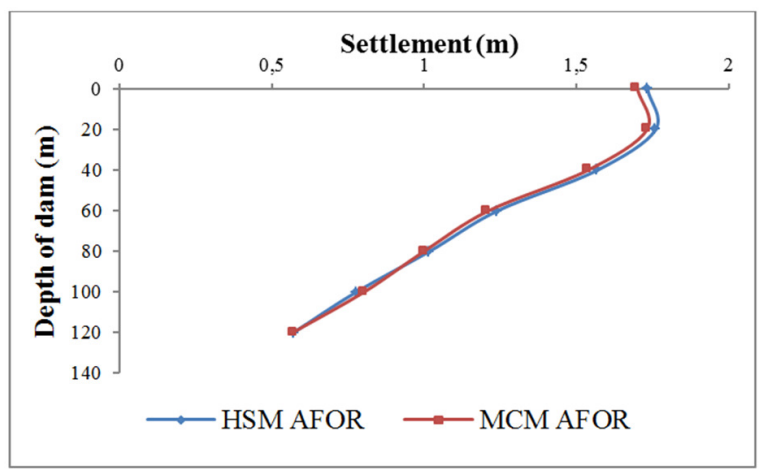

Fig. 6. Comparison of dam settlement with respect to depth computed for AFR with MCM and HSM applied to clay core only

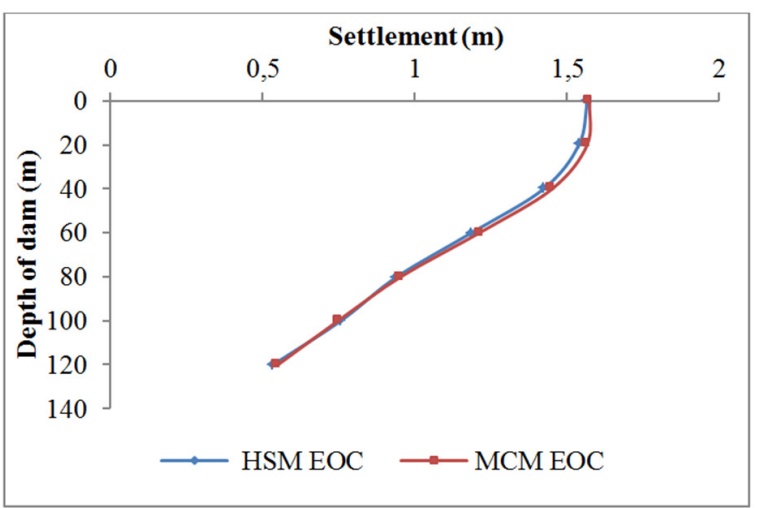

Fig. 7. Comparison of settlement of the dam with respect to depth for EC computed with MCM and HSM applied to sandy gravel only

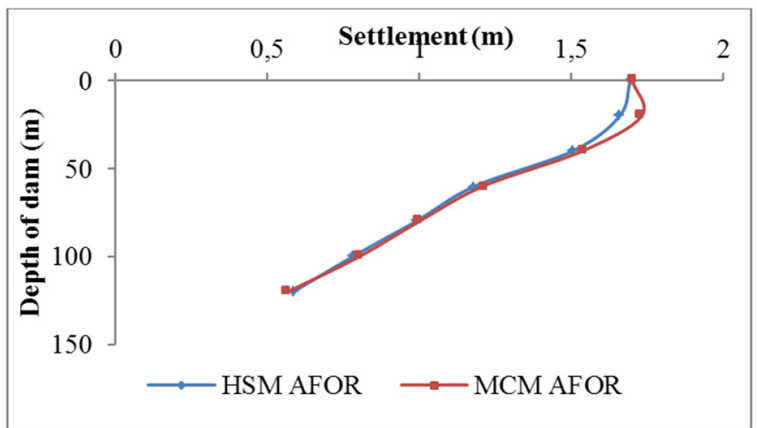

Fig. 8. Comparison of dam settlement with respect to depth for AFR computed with MCM and HSM applied to sandy gravel only

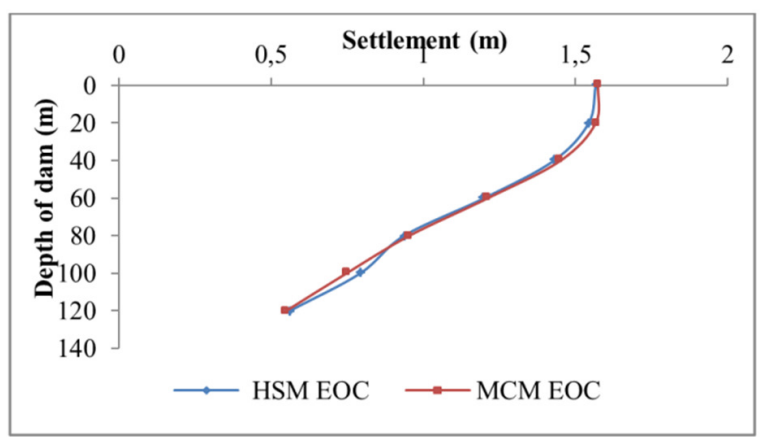

Fig. 9. Comparison of settlement of the dam with respect to depth for EC computed with MCM and HSM applied to random fill only

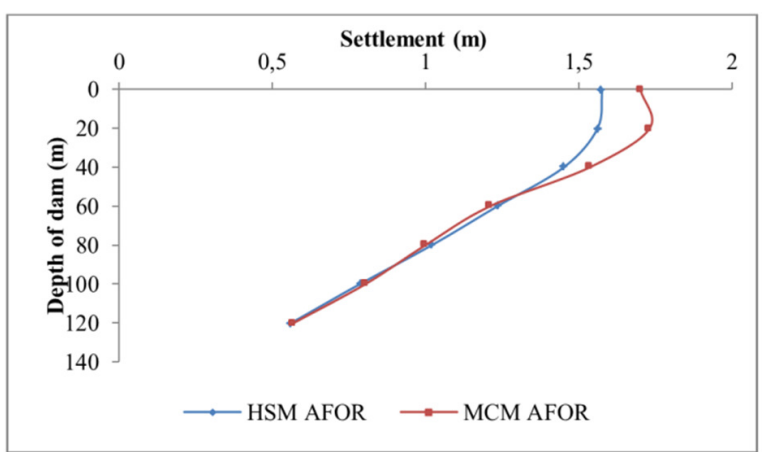

Fig. 10. Comparison of settlement of the dam with respect to depth for AFR computed with MCM and HSM applied to random fill only 
From the results it can be clearly observed that there is less variation in settlement with respect to depth when computed with MCM as compared to HSM computation for both EC and AFR for the four material zones (clay core, sandy grave and random fill). Figures 11 and 12 illustrate the dam settlement with respect to depth for EC and AFR, for conditions 1 and 2.

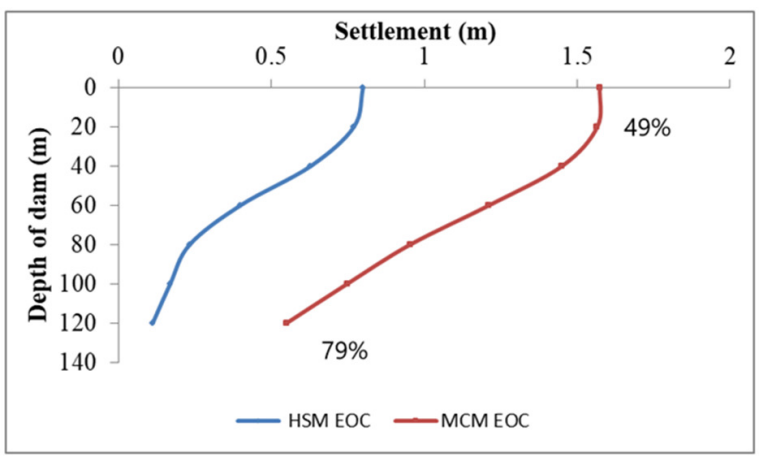

Fig. 11. Comparison of settlement of the dam with respect to depth for EC computed with MCM and HSM applied to sandy siltstone only

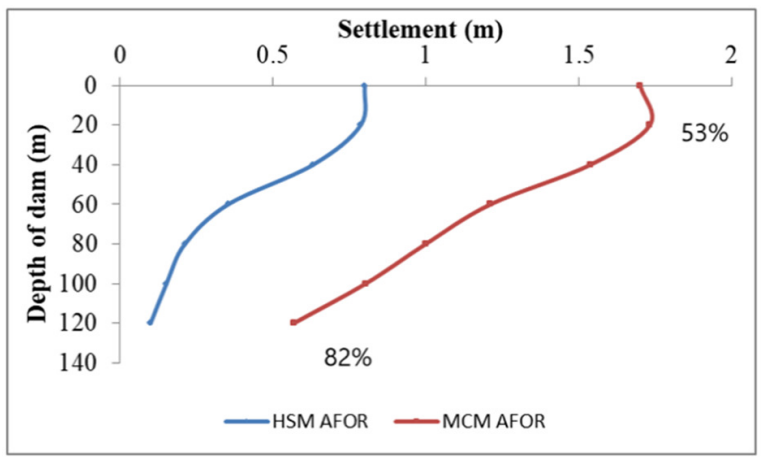

Fig. 12. Comparison of settlement of the dam with respect to depth for AFR computed with MCM and HSM applied to sandy siltstone only

There is a clear variation in settlement both at the crest of the dam and at the depth of $120 \mathrm{~m}$, because in HSM, the soil's MOE increases with respect to depth, which is a realistic soil behavior. Most of the dams exhibit settlement of about $1 \%$ of the total height of the dam [14]. The settlement of this dam computed with MCM and HSM for AFR was found to be $2.9 \%$ and $1.35 \%$ of the dam height respectively. By utilizing the HSM parameters as mentioned in this study, the settlement of the dam is considered to be in agreement with the literature findings. From the above results, it is observed that sandy siltstone has more influence on settlement with respect to depth of the dam as compared to the other material zones (clay core, sandy gravel, random fill) when computed with MCM and HSM. Therefore, the settlement response of sandy siltstone is further investigated in detail. For this purpose, the MOE of sandy siltstone varied from 70000 to $125000 \mathrm{kPa}$ and settlement with respect to depth was calculated using both MCM and HSM.

\section{B. Effect of Sandy Siltstone MOE Variation on the Settlement with Respect to Depth Using MCM and HSM}

The results of the comparison of the settlement of the dam at the crest and at the depth of $120 \mathrm{~m}$ computed under condition
1 and 2 for EC and AFR are presented in Figures 13 and 14. The MOE of sandy siltstone varied from 70000 to $125000 \mathrm{kPa}$ with increment of $10000 \mathrm{kPa}$. The results indicate that the rate of increase of the settlement computed with MCM (compared with HSM) increased with the depth of the dam. At the surface of the dam, the rate of increase of the settlement calculated with MCM (when compared with HSM) slightly decreased with increase of MOE. However, at the depth of $80 \mathrm{~m}$ and beyond the rate of increase of settlement computed with MCM is almost the same irrespective of any change in the MOE of sandy siltstone.

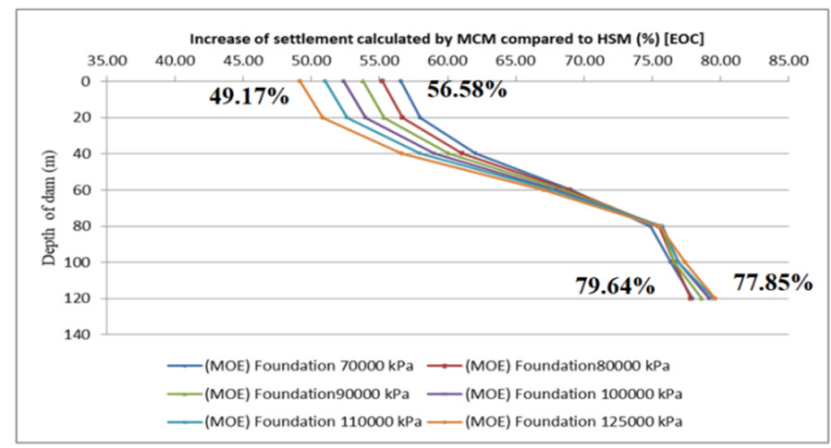

Fig. 13. Increase of EC settlement with respect to depth calculated by MCM and compared to HSM (\%)

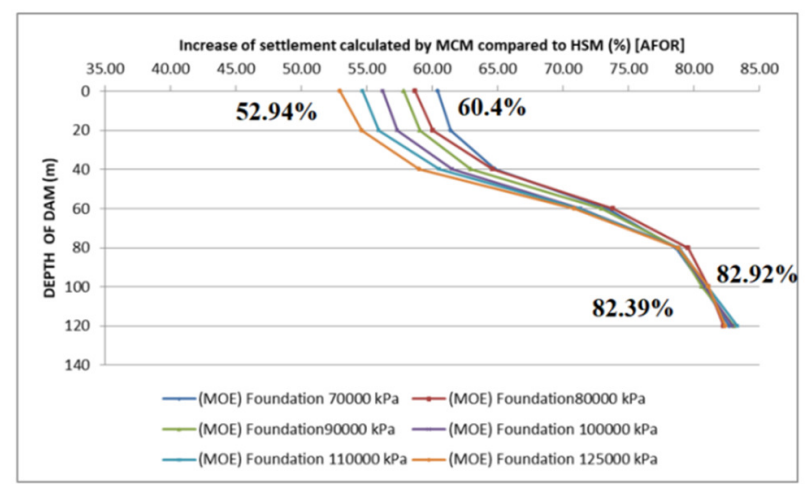

Fig. 14. Increase of AFR settlement with respect to depth calculated by MCM and compared to HSM (\%)

\section{MCM and HSM Applied to Sandy Siltstone Long-Term Settlement Comparison}

Long-term settlement of the dam was calculated even though the foundation is reported to be weak and fragile with open bedding planes, since it consists of sandy siltstone. The settlement of the dam was calculated for 50 years for both EC and AFR conditions using MCM (condition 1) and HSM (condition 2). The results are shown in Figures 15 and 16. The results suggest that long-term settlement of the dam is almost the same to the AFR settlement, even though the magnitude of the settlement predicted with MCM is higher than that of HSM. However, both models predicted that long term settlement did not increase with time. The long-term settlements predicted with MCM for both EC and AFR conditions was about 51\% and $59 \%$ higher than the ones predicted with HSM. The 
magnitude of the settlement is concentrated in clay core, sandy gravel, and random fill. The clay core is compacted during the construction process of the dam. However, clay is considered to be a compressible material, therefore the compression of the clay mostly occurred during construction and AFR phases. Therefore, further settlement of the clay did not occur during the long-term period of 50 years.

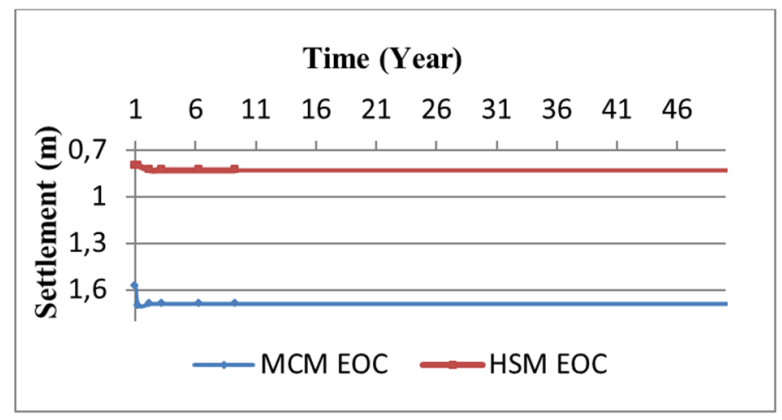

Fig. 15. Comparison of long-term settlement with MCM and HSM applied to sandy siltstone when the MOE is $125000 \mathrm{kPa}$

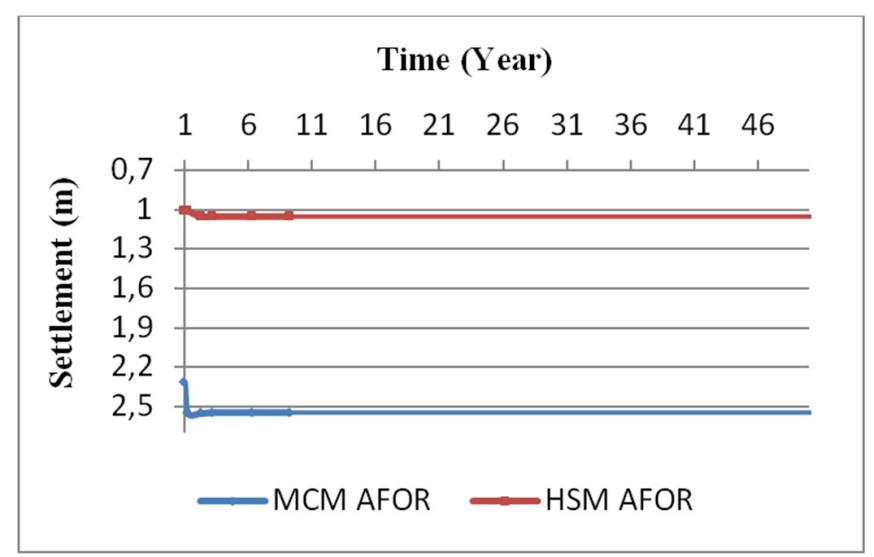

Fig. 16. Comparison of long term settlement with MCM and HSM applied to sandy siltstone when the MOE is $70000 \mathrm{kPa}$

\section{CONCLUSIONS}

Settlement with respect to depth and long-term settlement of an embankment dam were computed with MCM and HSM. The unrealistic settlement response predicted by MCM is due to the constant value of stiffness at all depths which is against real soil behavior. The HSM shows a settlement range which is in agreement with the literature even there is a limited availability of stiffness parameters. It would be more advantageous to use HSM instead of MCM for foundation soils because the former takes into consideration stress dependent stiffness.

\section{REFERENCES}

[1] V. Gikas, M. Sakellariou, "Settlement analysis of the Mornos earth dam", (Greece): Evidence from numerical modeling and geodetic monitoring", Engineering Structures, Vol. 30, No. 11, pp. 3074-3081, 2008

[2] R. Y. Liang, B. O. Nusier, A. H. Malkawi, "A reliability based approach for evaluating the slope stability of embankment dams", Engineering Geology, Vol. 54, No. 3-4, pp. 271-285, 1999
[3] A. D. Penman, "Instrumentation monitoring and surveillance", in: Embankment Dams, Routledge, 2018

[4] R. M. Roosta, A. Alizadeh, "Simulation of collapse settlement in rock fill material due to saturation", International Journal of Civil Engineering, Vol. 10, No. 2, pp. 93-99, 2012

[5] R. Mahinroosta, A. Alizadeh, B. Gatmiri, "Simulation of collapse settlement of first filling in a high rockfill dam", Engineering Geology, Vol. 187, pp. 32-44, 2015

[6] T. Schanz, P. A. Vermeer, P. G. Bonnier, "The hardening soil model: formulation and verification", in: Beyond 2000 in Computational Geotechnics, pp. 281-296, CRC Press, 1999

[7] Y. Hejazi, D. Dias, R. Kastner, "Impact of constitutive models on the numerical analysis of underground constructions", Acta Geotechnica, Vol. 3, No. 4, pp. 251-258, 2008

[8] R. B. Brinkgreve, "Selection of soil models and parameters for geotechnical engineering application", Geo-Frontiers Congress 2005, Austin, USA, January 24-26, 2005

[9] R. F. Obrzud, "On the use of the Hardening Soil Small Strain model in geotechnical practice", Numerics in Geotechnics and Structures, pp. 1532, Elmepress International, 2010

[10] R. B. J. Brinkgreve, S. Kumarswamy, W. M. Swolfs, Plaxis Reference Manual, PLAXIS, 2017

[11] N. Janbu, "Soil compressibility as determined by oedometer and triaxial tests", Proceedings of the European Conference on Soil Mechanics and Foundation Engineering (ECSMFE), Vol. 1, pp. 19-25, 1963

[12] P. V. Soos, "Properties of Soil and Rock", in: Grundbau Taschenbuch Part 4, Ernst \& Sohn, 1990 (in German)

[13] A. H. Bhutto, S. Zardari, M. A. Zardari, G. S. Bhurgri, B. A. Memon, R. Bhanbhro, M. M. Babar, "Mohr-Coulomb and Hardening Soil Model Comparison of the Settlement of an Embankment Dam", Engineering, Technology \& Applied Science Research, Vol. 9, No. 5, pp. 4654-4658, 2019

[14] G. Hunter, R. Fell, The Deformation Behaviour of Embankment Dams, The University of New South Wales, 2003

[15] A. Araei, "Artificial neural networks for modeling drained monotonic behavior of rockfill materials", International Journal of Geomechanics, Vol. 14, No. 3, Article ID 04014005, 2013

[16] ASCE Task Committee on Instrumentation and Dam Performance, Guidelines for Instrumentation and Measurements for Monitoring Dam Performance, ASCE, 2000 